\title{
Educação além da imagem
}

Resumo: A jornalista Lúcia Araújo, gerente-geral do Canal Futura - TV educativa gerida pela Fundação Roberto Marinho -, fala sobre os desafios e diferenciais de se administrar uma televisão voltada à educação no Brasil, comentando a maneira pela qual o público vê o tema e falando sobre o perfil do profissional necessário aos novos modelos de comunicação que surgem atualmente no mercado.

Palavras-chave: Televisão, educação, comunidade, jornalismo, terceiro setor.
Abstract: The journalist Lúcia Araújo, Futura Channel general manager - educational TV directed by Roberto Marinho Foundation talks about the challenges and differences to manage a television focused on education in Brazil, mentioning about the way the public sees the subject and talking about the professional profile required for the new communication models that appear on the market today.

Keywords: Television, education, community, journalism, third sector.

"O Brasil é um laboratório: tudo que der certo no Brasil, dará certo no mundo." Assim, a jornalista Lúcia Araújo, gerente-geral do Canal Futura, define o campo de atuação dentro do qual enfrenta os desafios e peculiaridades de realizar um trabalho educativo e comunicacional. Para além de um gerador de programas voltados à educação, o Canal, segundo ela, é aglutinador de um projeto social extenso, envolvendo o trabalho nas comunidades e a própria revisão do papel do comunicador - evolução dentro da qual, ela acredita, a Universidade tem papel fundamental. Nesta entrevista, Lúcia comenta as mudanças que tem visto à frente do Canal Futura na importância que se dá à educação no Brasil, ligando-as ao próprio desenvolvimento do país e do setor de comunicações.

Por Juliana Winkel

\section{Comunicação \& Educação - Quais são os principais desafios e objetivos de gerir um canal educacional no Brasil?}

Lúcia Araújo: Para mim, o grande privilégio é estar à frente de um canal inédito no mundo, voltado à comunicação e educação. Ou - e hoje usamos isso como uma moldura conceitual - um canal voltado para a transformação social, que é nosso objetivo maior. Essa moldura nos tira do conceito da TV educativa convencional, focada em transmitir conteúdos educacionais. Nós também fazemos isso, mas nossa singularidade é tudo que fazemos além disso.

O Futura é um canal grande, do ponto de vista de seu alcance, chegando a mais de 70 milhões de pessoas, entre a audiência por assinatura e via TV aberta. Temos hoje, pela televisão, um público de 2,4 milhões de educadores - número muito significativo, já que no universo da educação básica brasileira existem 4 milhões de educadores. Nossa equipe também é diferente da equipe de uma TV convencional. A TV Cultura, por exemplo, onde trabalhei por seis anos, tem 1.600 funcionários que fazem um canal muito bom, com coisas muito 
comunicação \& educação • Ano XVI • número 1 • jan/jun 2011

inovadoras. O Futura tem 100

funcionários fazendo TV, mas temos mais 50 que são educadores sociais, mobilizadores que ficam em diferentes partes do Brasil.

Por atuar junto a causas que aceleram ou retardam o desenvolvimento do país, o Canal tem o papel de aliado, por assim dizer, na construção da sociedade - junto a outras forças como o poder público, as empresas privadas e o terceiro setor. Como objetivo maior, está apoiar processos de desenvolvimento tendo a educação como prioridade. Não podemos encarar nossa missão, que é contribuir para a educação e para o desenvolvimento social do país, simplesmente como uma declaração de intencionalidade: precisamos transformá-la em algo concreto. Tudo que

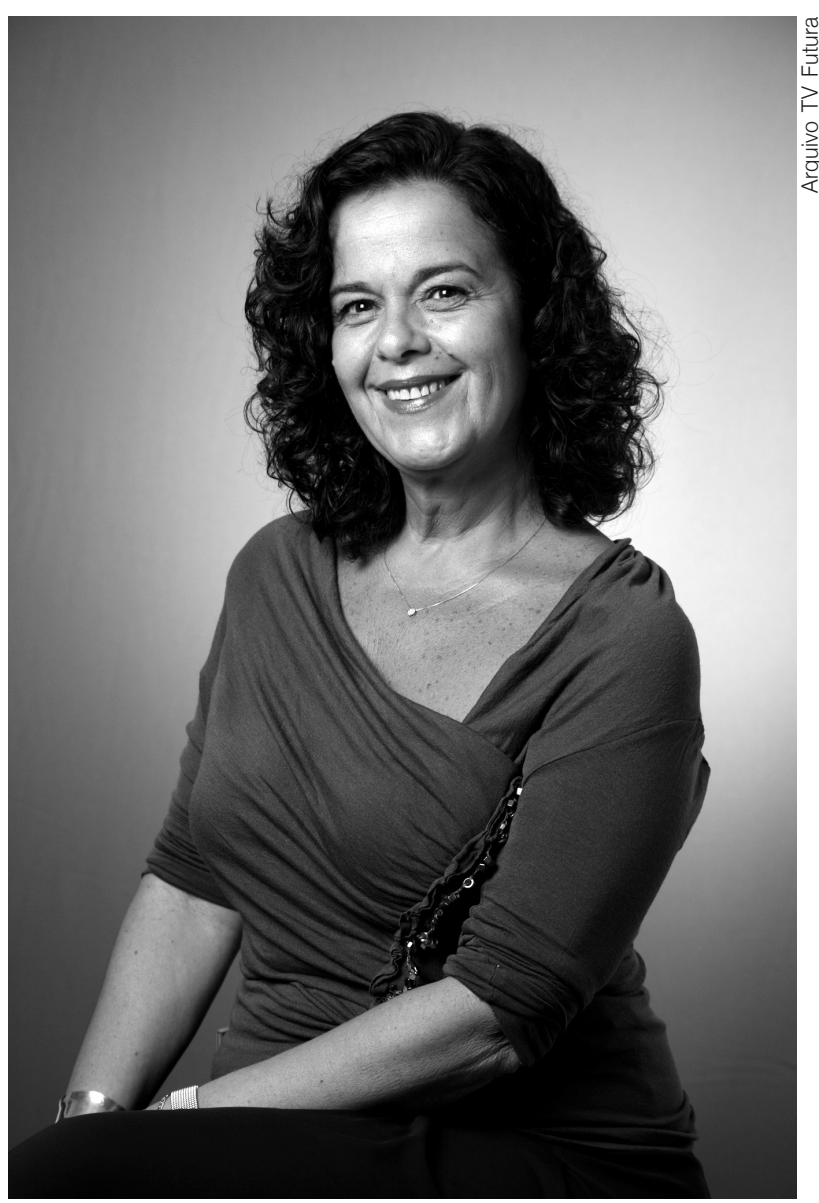

Lúcia Araújo: "Objetivo do Canal é o de aprofundar os temas, em articulação com outras organizações". fazemos, seja relativo a estratégias de programação, de produção de conteúdo ou de seu uso por diferentes segmentos da sociedade, compõe um conjunto de diretrizes específicas para cada caso, focadas no público que queremos atingir. Este conteúdo precisa chegar de fato aos educadores, indo além do que recebem pela própria tela da TV. Para isso, desenvolvemos projetos com escolas e com ONGs a partir das temáticas veiculadas na televisão.

Nesse sentido, o Canal tem um caráter complementar à informação, que é o de aprofundar os temas, abrir novas janelas. Temos, por exemplo, programas de viagem que não abordam o turismo convencional, mas sim lançam outro olhar sobre diferentes lugares. Pela resposta positiva do público, percebemos que existe demanda para isso - assim como para cursos profissionalizantes. Temos uma série deles em parceria com o Sebrae, sobre a abertura de novas empresas e empreendedorismo.

A intenção dessas diferentes estratégias é atingir mães e pais de família, professores, estudantes, mas, sobretudo, o brasileiro que está na base da pirâmide, que quer se educar, se reciclar, melhorar de vida, saber abrir um negócio, falar melhor português. Cerca de $70 \%$ do nosso público, de modo geral, 
está nas classes C, D e E. A maioria, quase $80 \%$, tem o Ensino Médio e está buscando entrar na universidade. Então, ao mesmo tempo que a programação tem a conotação de debate dos temas que interessam, também tem um lado pragmático, voltado aos telespectadores que querem ferramentas para prosperar, e sabem que precisam da educação para isso. Procuramos fazer programas que não poderiam estar em nenhum outro canal. Ao assisti-los, você pensa sobre sua vida, sobre seu país e tem mais referências para a hora em que for votar, por exemplo. Tudo isso é educação. Existe a educação escolar, formal, e a educação informal. Nós atuamos nas duas.

C\&E - Quais são as estratégias específicas do Canal voltadas para o trabalho com educadores?

L.A. - Produzimos um programa chamado Globo Educação, que vai ao ar tanto pelo Futura quanto pela Globo. Isso nos obrigou a mergulhar profundamente na área. Mas, ao longo da sua existência, o Futura também tem trabalhado com os profissionais de forma contínua. O conteúdo do Canal é criado tanto para ser veiculado na TV como de forma a possibilitar apropriações para usos específicos, em trabalhos com a comunidade. Uma das principais ações organizadas a partir deste conteúdo é a Maleta Futura, que distribuímos para escolas ou ONGs de acordo com cada tema. Saúde, por exemplo, é um campo em que as ONGs atuam mais do que as escolas, por isso direcionamos a Maleta Saúde para elas. Já a Maleta Democracia, que aborda educação para a política, é mais direcionada aos professores. A Cor da Cultura, outro projeto no qual falamos de identidade africana, também tem como alvo as escolas.

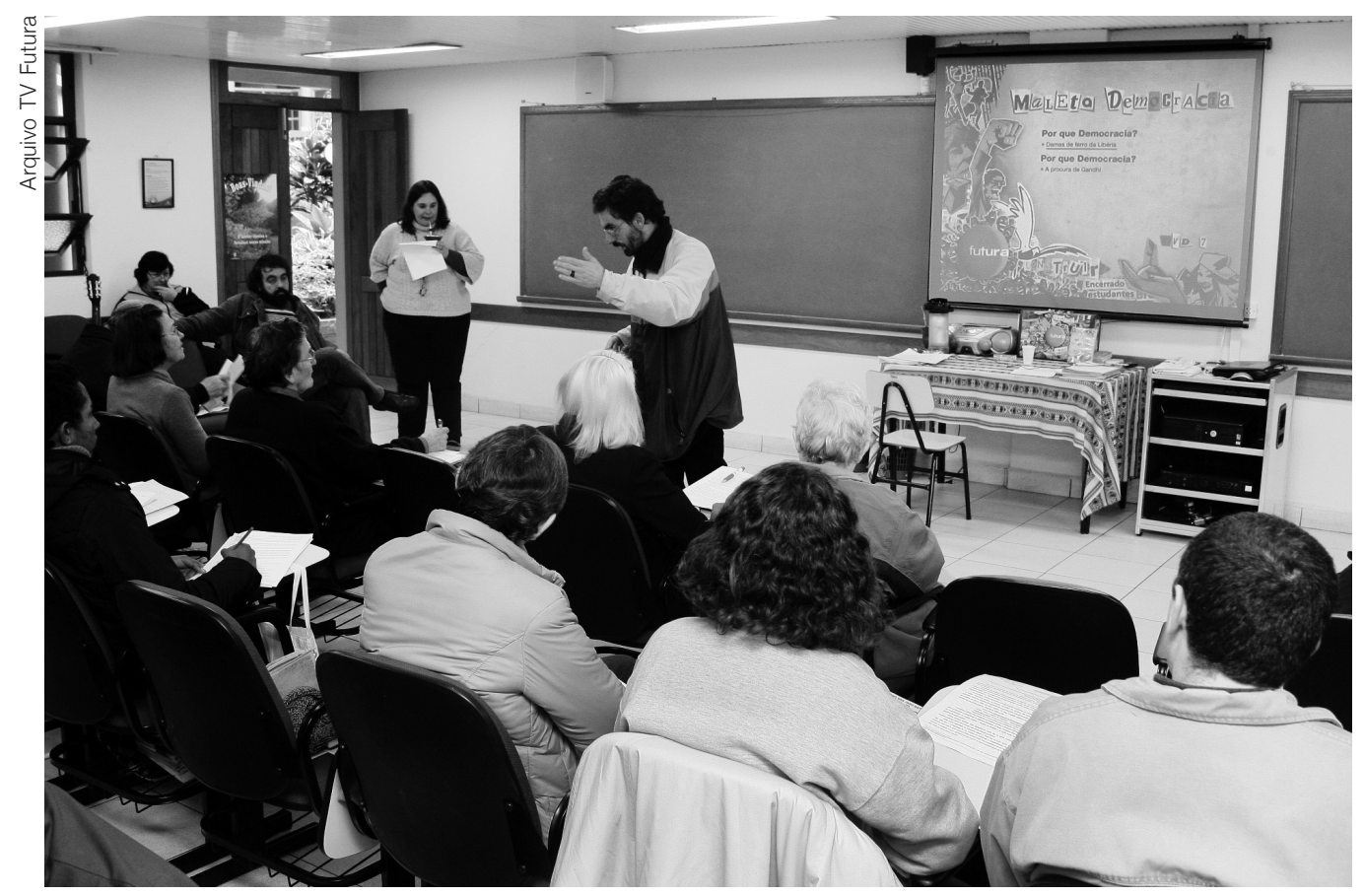

Participantes de movimentos comunitários estudam o conteúdo da Maleta Democracia: informação da TV é vivenciada na prática. 
comunicação \& educação • Ano XVI • número 1 • jan/jun 2011

Depois de distribuídos, acompanhamos o trabalho com esses materiais de forma presencial e on-line, por meio do endereço <www.conexaofutura.org.br $>$. Pelo site, fazemos o monitoramento do uso das Maletas. Há, por exemplo, a Maleta Toda Beleza, que discute a questão da Estética enquanto um campo da filosofia: o valor da beleza, o que é belo, o que não é, a beleza e o consumo, e assim por diante. Temos no site a relação de todas as ONGs e escolas que receberam a Maleta e quais os programas mais assistidos relacionados a ela - da mesma forma como fazemos com as Maletas de meio ambiente, democracia, saúde.

Outra forma de acompanhar o trabalho é por meio dos mobilizadores sociais, que nos informam sobre as instituições referenciadas para receber o material. As Maletas distribuídas no estado de Pernambuco, por exemplo, foram acompanhadas por uma mobilizadora do Futura que identificou e capacitou essas instituições, realizando reuniões e discussões para troca de experiências.

\section{C\&E - Existem estratégias específicas envolvendo o público televisivo pela Internet?}

L.A. - Temos estratégias específicas tanto para a internet como para o público jovem que está nas redes. Por exemplo, veiculamos um programa sobre língua portuguesa chamado Afinando a língua, apresentado pelo Tony Bellotto, dos Titãs. É um programa que usa a música para explorar aspectos da língua portuguesa e da literatura, e do qual participam bandas amadoras. Fizemos, a partir dele, um concurso de bandas via Twitter. $\mathrm{O}$ resultado foi impressionante: tivemos milhões de pessoas participando, assim como nos blogs. Estamos também desenvolvendo um jogo na Internet para os adolescentes.

Outra estratégia importante é o Futuratec, um acervo de programas disponível pelo site <www.futuratec.org.br>, a qualquer pessoa que pertença a uma instituição - escola, ONG, hospital, creche, ligado ou não ao canal. São mais de 400 horas digitalizadas para download, muito utilizadas por universidades e escolas. O professor Renato Janine, por exemplo, que é nosso apresentador, fez uma série de programas sobre ética - abordando a microética, a ética do cotidiano -, que teve muito sucesso. São alguns dos mais baixados pela Internet.

É interessante ver, inclusive, como se processa a busca de material pela Internet. Pela procura, percebemos que é grande a necessidade de canais credenciados onde as pessoas possam buscar informação. Procuramos estar sempre em dia com o envio de informações para os blogueiros, por exemplo, porque é comum publicarem nossos releases e agendas na íntegra, o que, nesse caso, é muito bom.

\section{C\&E - Qual o papel dos índices de audiência em um canal com objetivos não comerciais?}

L.A. - O Ibope, para nós, é secundário. Fazemos a medição, mas nossa medida de sucesso não é essa. É preciso desenvolver uma série de outras réguas para verificar o verdadeiro impacto social que o canal tem. O Futura é, por exemplo, o único do Brasil que realiza uma pesquisa econométrica, medindo o valor de impacto social do canal em reais. 


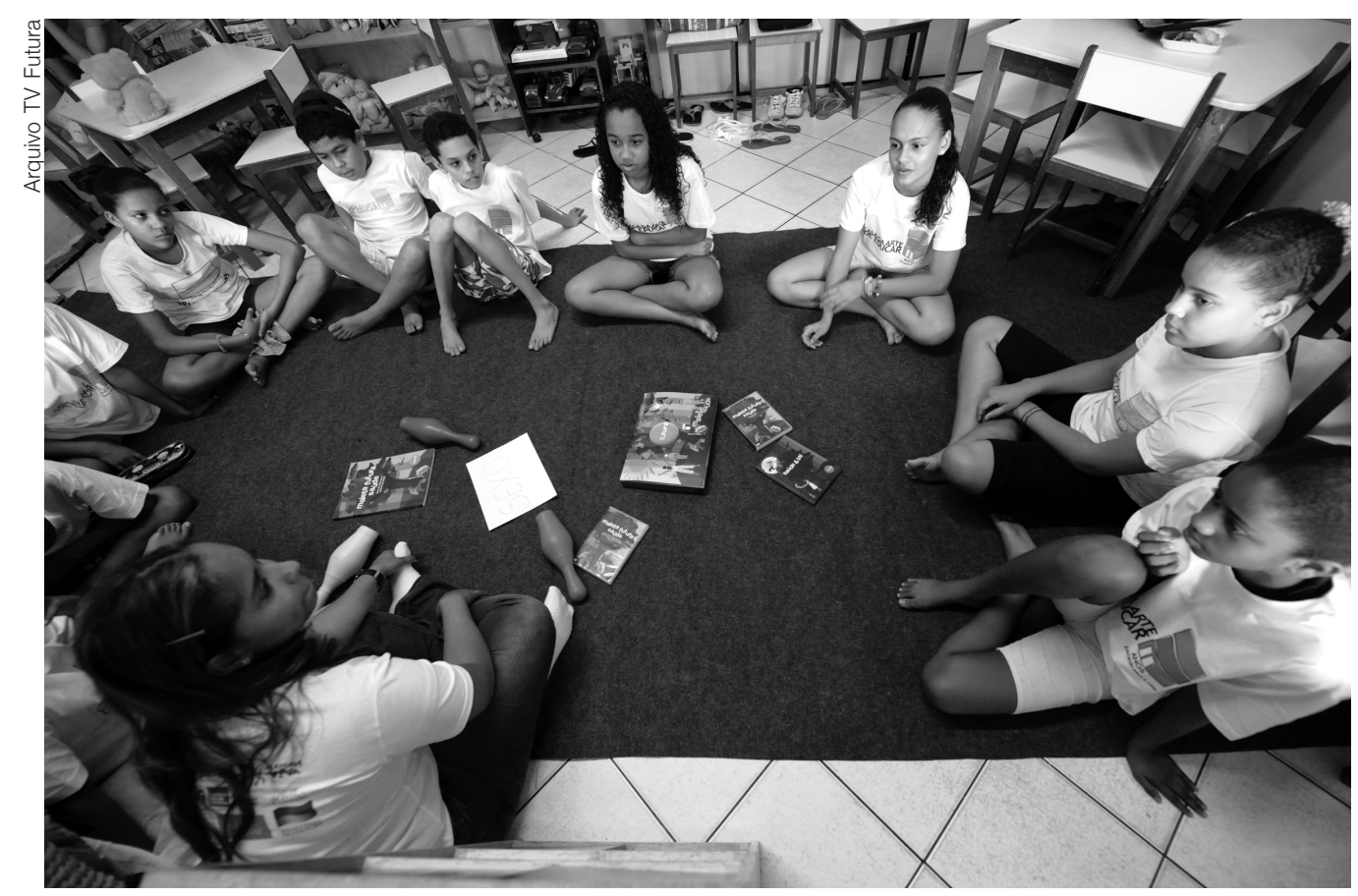

Jovens participam de atividades com base no conteúdo da Maleta Futura Saúde.

Temos mais de 40 milhões de pessoas que acessam o Canal Futura por meio de parabólica. É nosso maior público, além dos lugares onde temos o sinal aberto em UHF ou VHF. Todos os canais que nos retransmitem em sinal aberto são universitários. Temos 26 universidades com canais de circuito interno, abertos, ou com produção de conteúdo audiovisual próprio.

Depois de doze anos, temos um retorno muito importante sobre o público telespectador, que nenhuma pesquisa nos dá. Esse retorno vem por meio do nosso mobilizador, que conhece todas as instituições: a ONG que trabalha com jovens vítimas de exploração sexual, a escola que desenvolve um trabalho de educação artística ou de excelência matemática. O Futura não quer ser uma TV grande: quer ser pequena, mas sempre trabalhando em articulação com outras organizações. A partir do conhecimento dos territórios, passamos a coproduzir com várias instituições, estejam elas no semiárido, no sertão ou na Amazônia. São parceiros de produção que incorporam ao nosso conteúdo a contribuição de diversos segmentos da sociedade. Essas contribuições voltam para a TV, formam o círculo virtuoso. Durante todo o tempo, o trabalho que está acontecendo no solo - na ONG, no hospital - volta como informação para melhorar a própria programação do Canal.

Antes de o Futura nascer, foi feita uma pesquisa perguntando aos brasileiros o que eles assistiam de educativo na TV. Transpareceu o conceito de que o tema é como remédio: importante, mas ninguém gosta. E quando foi perguntado às pessoas qual programa era considerado mais educativo, em primeiro lugar foi citado o Globo Repórter e, em segundo lugar, o Brasil Legal, apresentado pela Regina Casé. Veja que curioso: as pessoas identificaram esses programas com 
comunicação \& educação • Ano XVI • número 1 • jan/jun 2011

o conteúdo enriquecedor do ponto de vista educativo, embora não tenham sido feitos com o objetivo de ensinar. É isso que procuramos fazer: programas interessantes de se assistir e que também contribuam para o aperfeiçoamento pessoal, do cidadão, do profissional, da criança. Precisamos fazer uma programação que, de alguma forma, atenda o grande público de educadores e também o público em geral. Mas, antes de tudo, temos que pensar em fazer um bom programa, independentemente do fato de estarmos num ambiente de educação. Ele tem que comover, divertir, trazer informações, surpreender, senão a pessoa muda de canal. O público brasileiro é muito bem alfabetizado visualmente. Não adianta levar lixo cheio de boas intenções.

\section{C\&E - Para que isso funcione, foi necessário rever a maneira de se fazer comunicação em grande escala?}

L.A. - Acredito que o diferencial do Canal foi ter inventado um modelo de gestão. O Futura tem um forte relacionamento acadêmico, inclusive com a Intercom - Sociedade Brasileira de Estudos Interdisciplinares da Comunicação, da qual fui uma das fundadoras. Na Intercom, já se chegou à conclusão de que uma das ausências dos cursos de comunicação é a gestão. No curso, só se aprende a "apertar um tipo de parafuso" da profissão. Não se aprende a pensar em um negócio de comunicação. Então a gestão torna-se um grande desafio, principalmente quando se quer fazer um canal que não seja óbvio. Aqui estamos sempre revendo nosso modelo de gestão, o que acho ótimo - porque, a cada nova situação, vamos criando novas maneiras de dividir, pensar e organizar o trabalho. Gerir um canal que trabalha em cooperação com diferentes agentes sociais é sempre um grande desafio. Um projeto como A Cor da Cultura, por exemplo, feito junto com o MEC sobre a identidade africana, envolveu mais de 50 consultores. Imagine o que é mediar uma relação envolvendo ONGs, universidade, governo, pessoas de direita, esquerda.

Costumo dizer que uma das questões fundamentais do modelo de gestão é a mediação de interesses e conflitos. Porque o Futura, ao mesmo tempo que é parceiro e trabalha junto com a iniciativa privada, através de fundações e institutos, também trabalha com ONGs da Amazônia, com a Casa de Passagem de Recife, que acolhe jovens vítimas de exploração, com a tribo dos Pataxós da Bahia e com o produtor independente. Não temos grandes estruturas de estúdio e não pretendemos ter. Queremos justamente incrementar o mercado brasileiro de produtoras, que é muito bom. O modelo de gestão, então, parte da pergunta: o que de fato depende de nós exclusivamente? Qual o sentido da nossa presença, seja numa televisão, seja numa ação social? Determinar as diretrizes estratégicas, pensar nos approaches conceituais, tudo isso temos que administrar. Mas quem vai efetivamente fazer isso são nossos parceiros, dos mais variados perfis possíveis. Nossa tarefa é criar e administrar conceitos e conteúdos. E, além disso, zelamos pelo processo e acompanhamos a qualidade.

Outro desafio enorme do nosso modelo de gestão é como incorporá-lo a todos os colaboradores do Futura - envolvendo desde a produção até a coordenação de uma ação conjunta. Como a cada dia temos novas ações, não é 
o modelo de gestão que manda em nós, nós é que mandamos no modelo de gestão - claro, dentro dos balizamentos da Fundação Roberto Marinho, que é uma fundação de direito privado, mas com uma série de obrigações públicas. Nosso grande framework é o ambiente de terceiro setor.

C\&E - Você comentou sobre a ausência da formação em gestão para profissionais de comunicação. Qual considera o perfil de profissional adequado para atuar nesse novo modelo?

L.A. - É um desafio, para nós, encontrar profissionais com visão ampla no mercado. O tempo todo temos que formar profissionais no perfil de que precisamos: que tenham o domínio das ferramentas da comunicação, incluindo análise, apuração, identificação - mas que, além disso, lidem com ferramentas de ação social. Para saber até onde podemos ir nessa formação, é essencial ter a humildade de reconhecer que os conhecimentos de que necessitamos estão espalhados em vários lugares e temos que identificá-los. Atualmente, por exemplo, desenvolvemos uma experiência muito interessante junto ao curso de filosofia da Universidade Federal do Rio de Janeiro. Estamos produzindo uma série infantil e eles testam a receptividade junto às crianças antes de ela ser finalizada.

Procuramos, assim, realizar laboratórios interdisciplinares pensando na gestão de processos comunicacionais - porque não tenha dúvida de que tudo isso é comunicação, e não só comunicação midiática, mas também interpessoal e interinstitucional. Que tipo de competências um profissional precisa para se relacionar, ao mesmo tempo e em profundidade, com uma ONG, uma empresa privada, com o setor público e com uma agência internacional? É um trabalho complexo, que vai além do perfil de um profissional convencional da comunicação. Nós, aqui, estamos na fronteira da comunicação, que tem como obrigação pública informar bem, verificar o maior número de lados possível e em profundidade. Então, é fundamental nos abrirmos para os diferentes olhares, fazendo nosso papel de transformar isso num produto para o público.

Por outro lado, acho que a universidade também faz pouco essa intersecção. Ela tem o conhecimento instalado nas diferentes áreas do saber - ciências sociais, direito, biologia - e que, muitas vezes, é uma descoberta para os próprios acadêmicos dos outros campos. Quando mais diferente a área, melhor é o diálogo, porque deixamos de olhar apenas o nosso próprio ponto de vista - além de ser uma forma de a academia se aproximar do campo, dois lados que, na maioria das vezes, vivem divorciados e são ambos prejudicados por isso.

O comunicador ainda é muito autorreferido. Costumo dizer que a comunicação é a única carreira em que o profissional encara de forma negativa sua própria área de trabalho. Ao conviver com os comunicadores, tenho a sensação de que são todos inimigos do mercado - e todos perdem com isso. Eu acho maravilhoso que hoje se possa estar no Movimento dos Trabalhadores Sem Terra, nos blogs e também nas empresas. Existem muitos lugares para se trabalhar e não é preciso ser contra o mercado de trabalho. O que ocorre é que os profissionais estão perdendo a capacidade de reflexão que a universidade 
comunicação \& educação • Ano XVI • número 1 • jan/jun 2011

ajuda a proporcionar. Ela organiza o conhecimento e abre espaço de debate, algo que tem de se incorporar à rotina dos comunicadores. E a universidade, por sua vez, perde a grande chance de observar in loco o fenômeno social e sua formatação, assim como a capacidade de influenciá-lo também.

\section{C\&E - Você acha que a consciência com relação à importância da Educação tem aumentado entre a população de maneira geral?}

L.A. - Acredito que a boa notícia é que existe uma consciência maior da sociedade brasileira como um todo, em todos os segmentos - público, privado, sociedade civil -, quanto à importância da educação. A má notícia é que, apesar desta unanimidade, os resultados são ainda muito lentos. De qualquer forma, sabemos que esse não seria um processo rápido: não se pode perder a perspectiva histórica. Se por um lado, nos últimos dez anos, não avançamos tanto quanto achávamos que devíamos avançar - e certamente poderíamos ter avançado mais -, por outro, se observarmos os últimos 50 ou 100 anos, veremos que já avançamos muito. A escola da qual temos saudade, que nos traz nostalgia, era uma escola elitista. Nós atingimos a universalização e, agora, temos que refinar as nossas demandas. A questão da baixa qualidade é inaceitável no Brasil. Somos a décima economia do mundo e estamos em $76^{\mathrm{o}}$ lugar no Programa Internacional de Avaliação de Alunos, PISA, o índice mundial de escolaridade medido a cada dois anos. Aí está o retrato da nossa desigualdade. Não é possível que a Suécia tenha onze anos de escolaridade média e o Brasil tenha seis. Para estar à altura da sua posição econômica, o Brasil tem que se preparar educacionalmente. E temos uma coisa muito positiva, que o Ministério da Educação inclusive soube reconhecer: um terceiro setor dos mais ativos do mundo, que faz com que a política pública encontre aliados fortes nas Fundações e nas ONGs. Educação é a tônica do terceiro setor: $70 \%$ dos projetos estão nessa área. Houve, por exemplo, um concurso para professores de língua portuguesa desenvolvido pela Fundação Itaú Social, que capacitava escolas com kits para a melhoria da questão do uso da língua. Os resultados foram tão bons que o MEC adotou este programa, no formato de uma olimpíada de língua portuguesa. Com esse tipo de ação, as experiências que oferecem potencial podem ganhar escala nacional.

O Brasil é um laboratório: tudo que der certo no Brasil, dará certo no mundo. As singularidades do país são muitas, a começar pelos números: 50 milhões de alunos nas escolas públicas. Esse número é maior do que a maioria das populações dos países desenvolvidos. E dentro disso, temos os índios, os portadores de necessidades especiais, as questões regionais... é um país muito complexo, com muita gente atuando nas mais diversas frentes: saúde, ação social, direitos humanos, educação.

Então o Brasil tem que gostar mais de si mesmo e ter orgulho daquilo que faz. Nesse ponto, a cooperação da universidade é fundamental. A professora que ganhou o prêmio Nobel de economia em 2009, Elinor Ostrom, é uma cientista social - o que já é um sinal positivo para a questão da interdisciplinaridade. Ela provou que arranjos cooperativos de comunidades de áreas de preservação 
ambiental podem ser muito bem-sucedidos e ajudar a própria sustentabilidade ambiental. Por exemplo, um grupo de pescadores que se organizou em conjunto com uma ONG, ou uma empresa, conseguiu desenvolver uma maneira de pescar e de exportar sardinha, e o dinheiro recebido está servindo para melhorar a educação. No programa especial que realizamos com ela para o Dia da Mulher, ela afirmou que seu único mérito foi a cumulação de tudo que já tinha sido estudado. Pesquisando o assunto de sua tese, descobriu que alguém em uma universidade de Tóquio tinha analisado o trabalho dos pescadores. Viu que havia economistas fazendo isso também nos Estados Unidos, sociólogos estudando pescadores no Brasil, biólogos pesquisando o mesmo no Chile. Fez, então, um mapeamento de tudo que havia sobre arranjos cooperativos em áreas de preservação ambiental. É importante que alguém junte o que foi separado, muitas vezes, até por motivos metodológicos. Precisamos combater os reflexos da compartimentação excessiva, criando oportunidades para que todos tenham interesse de olhar para o mesmo fenômeno.

Quando se examina os países participantes do PISA, percebe-se um dado fundamental: o lugar que cada sociedade dá à educação. Na Finlândia, os melhores professores são os melhores alunos das universidades - porque a sociedade colocou a escola em um patamar de respeito. Quando o profissional sai da universidade, ele quer dar aulas. No Brasil, ninguém quer ser professor. A profissão se desglamorizou, empobreceu, se esvaziou. A sociedade de modo geral tem a ver com isso, mas acho que a universidade tem em si um grande papel no resgate do valor da educação. Já mostramos experiências de universidades trabalhando junto com escolas, com resultados sensacionais. A universidade tem papel fundamental em requalificar o papel da escola, e não apenas por meio do curso de pedagogia, mas de todos. 


\section{ConTos DE Hans Christian Andersen}

A vida do grande escritor dinamarquês mais parece um conto de fadas. Nasceu pobre, ficou órfão e desvalido, mas transformou-se em escritor mundialmente querido, traduzido para todas as línguas. Agora, parte de seu fabuloso universo de contos infantis criado há quase dois séculos chega por Paulinas em obra traduzida diretamente do dinamarquês.

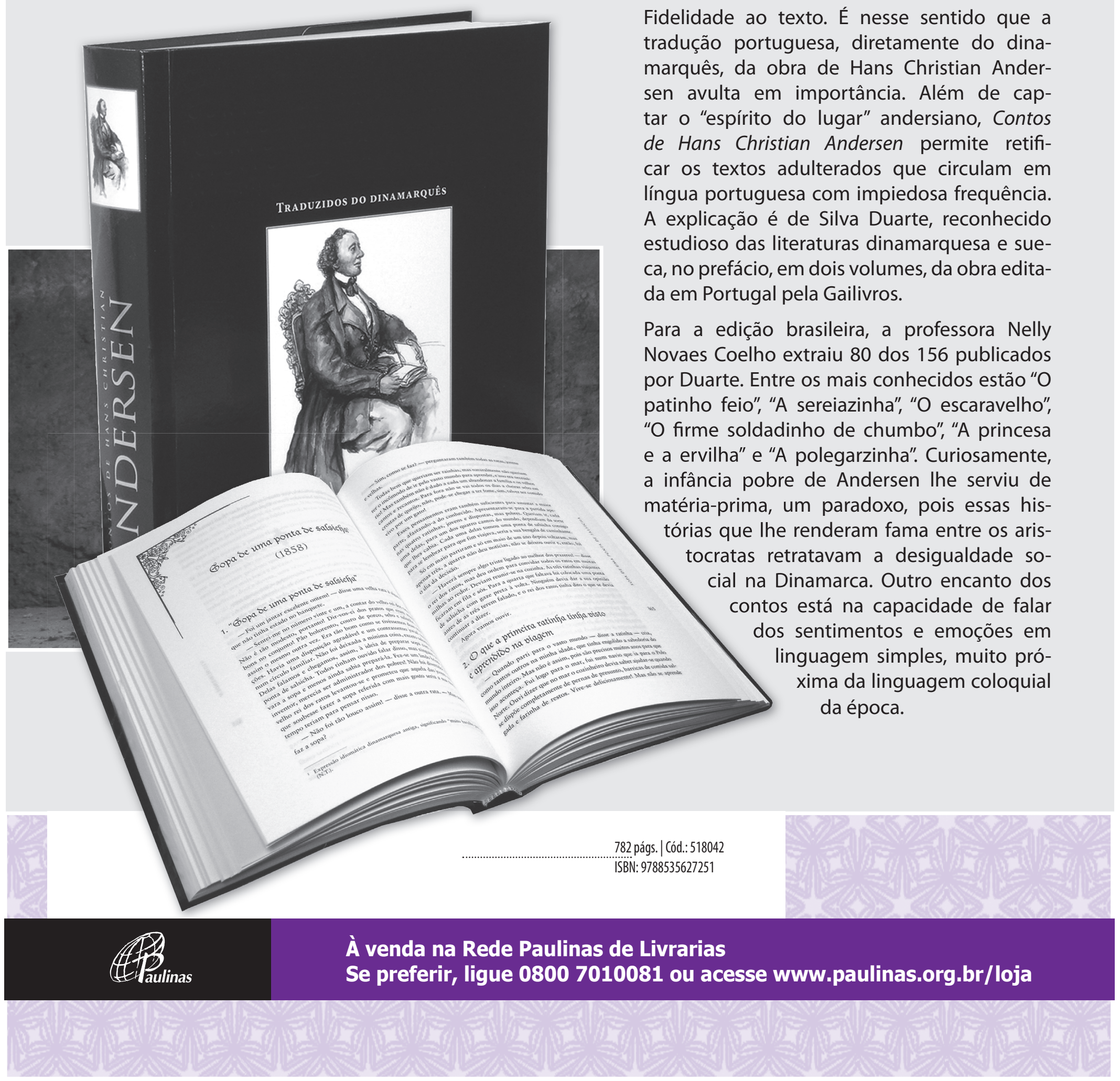

